\title{
Comparison of Antimicrobial Activity of Chlorhexidine, Coconut Oil, Probiotics, and Ketoconazole on Candida albicans Isolated in Children with Early Childhood Caries: An In Vitro Study
}

\author{
Beena Shino, ${ }^{1}$ Faizal C. Peedikayil, ${ }^{1}$ Shyamala R. Jaiprakash, ${ }^{2}$ \\ Gufran Ahmed Bijapur, ${ }^{2}$ Soni Kottayi, ${ }^{1}$ and Deepak Jose ${ }^{1}$ \\ ${ }^{1}$ Department of Pedodontics, Kannur Dental College, Kerala 670612, India \\ ${ }^{2}$ Department of Microbiology, Kannur Medical College, Kerala 670612, India \\ Correspondence should be addressed to Beena Shino; beenamol40@yahoo.in
}

Received 21 December 2015; Accepted 25 February 2016

Academic Editor: Paul O. Gubbins

Copyright (C) 2016 Beena Shino et al. This is an open access article distributed under the Creative Commons Attribution License, which permits unrestricted use, distribution, and reproduction in any medium, provided the original work is properly cited.

Background. Early childhood caries (ECC) is associated with early colonisation and high levels of cariogenic microorganisms. With C. albicans being one of those, there is a need to determine the effectiveness of various chemotherapeutic agents against it. The study is aimed at isolating Candida species in children with ECC and at studying the antifungal effect of coconut oil, probiotics, Lactobacillus, and $0.2 \%$ chlorhexidine on C. albicans in comparison with ketoconazole. Materials and Methods. Samples were collected using sterile cotton swabs, swabbed on the tooth surfaces from children with ECC of 3 to 6 yrs and streaked on Sabouraud dextrose agar (HI Media) plates and incubated in a $5 \% \mathrm{CO}_{2}$ enriched atmosphere at $37^{\circ} \mathrm{C}$ for 24 hours. Candida was isolated and its susceptibility to probiotics, chlorhexidine, ketoconazole, and coconut oil was determined using Disc Diffusion method. Results. The mean zone of inhibition for chlorhexidine was $21.8 \mathrm{~mm}$, whereas for coconut oil it was $16.8 \mathrm{~mm}$, for probiotics it was $13.5 \mathrm{~mm}$, and for ketoconazole it was $22.3 \mathrm{~mm}$. The difference between the groups was not statistically significant (Chi-square value 7.42, $P$ value 0.06). Conclusion. Chlorhexidine and coconut oil have shown significant antifungal activity which is comparable with ketoconazole.

\section{Introduction}

The disease of early childhood caries (ECC) is defined as the presence of one or more decayed (noncavitated or cavitated lesions), missing (due to caries), or filled tooth surfaces in any primary tooth in a child 71 months of age or younger. In children younger than 3 years of age, any sign of smooth surface caries is indicative of severe early childhood caries (S-ECC) [1]. It is associated with early colonisation and high levels of cariogenic microorganism, high levels of dental plaque, enamel defects in the primary teeth, and childhood diets rich in sugar and carbohydrate. These primary risk factors interact to produce an acidic environment in the dental plaque causing decalcification of enamel and dentin. Streptococcus mutans, Lactobacilli, and Candida albicans are the predominant microorganisms found in dental plaque associated with a caries lesion [2]. Several antimicrobial agents have been introduced with the goal of suppressing the cariogenic bacteria, resulting in a remarkable reduction in S. mutans levels [3]. The contribution of C. albicans to overall microbial acid formation appears to be important, as it ferments glucose and maltose, producing both acid and gas [4]. The presence of Candida has been shown to enhance the adherence of $S$. mutans to the oral biofilm and carious tooth substance in vitro [5]. Research on the chemotherapeutic approaches to prevent or reduce the levels of $C$. albicans resulting in ECC has been limited, and there is a need to determine the effectiveness of various chemotherapeutic agents against C. albicans to reduce the caries experience in children.

Antifungal agents, such as azoles (fluconazole, ketoconazole) and polyenes (amphotericin B or nystatin), are commonly used to control the candidal infections [6]. Chlorhexidine has a wide spectrum of antimicrobial activity and is used 
as a topical therapeutic supplement. It is also capable of inhibiting the candidal adhesion to biological and inert surfaces [7]. Coconut (Cocos nucifera) is the unique source of various natural products, useful for the development of medicines against various diseases. The parts of its fruit like coconut kernel and tender coconut water are of a great medicinal value because of its antimicrobial and antioxidant property [8]. Probiotic bacteria have been used to modify microfloral ecosystems and have shown some success as a therapeutic for oral diseases [9].

This study aims to test the susceptibility of C. albicans isolates from children with ECC to the antifungal, ketoconazole, mouth rinse, chlorhexidine, coconut oil, and probiotic and to compare their antimicrobial efficacy.

\section{Materials and Methods}

Children with early childhood caries (ECC) in the age group of 3 to 6 yrs consulting the Outpatient Department of Pediatric And Preventive Dentistry, Kannur Dental College, Anjarakandy, are taken as subjects for the study. Children who were on topical or systemic antibiotics or antifungals are excluded from the study. Informed written consent was obtained from the accompanying parent/guardian of the child. The caries experience (dmfs index) of the children was recorded using visible light, mouth mirror, and CPI probe and based on the caries experience children with ECC were selected for the study.

Samples were collected using sterile cotton swabs, swabbed over the buccal, lingual, proximal, and cervical portion of the teeth, and were immediately transferred to the lab for microbiological analysis. The samples were streaked onto Sabouraud dextrose agar (HI Media) plates supplemented with antibiotics (chloramphenicol $50 \mu \mathrm{g} / \mathrm{dL}$ ) and incubated in a $5 \% \mathrm{CO}_{2}$ enriched atmosphere at $37^{\circ} \mathrm{C}$ for 24 hours and left at room temperature for further 24 hours. Growth of Candida appeared as cream or white coloured, smooth, and pasty colonies (Figure 1). Culture is said to be negative if there is no growth even after 72 hours of incubation. Candidal species identification is done by Germ tube test and morphology on corn meal agar (Dalmau Plate Culture method) read after 48 hours. Twenty such positive samples of C. albicans were obtained.

Antifungal activity of $2 \%$ ketoconazole $\left(\operatorname{Kevon}^{\mathrm{R}}\right), 0.2 \%$ chlorhexidine (Hexidine mouthwash), probiotics (Vizylac ${ }^{\mathrm{R}}$, lactic acid Bacillus $120 * 10^{6}$ ), and coconut oil against C. albicans is tested by Kirby Bauer's Disc Diffusion method. 0.2\% chlorhexidine, coconut oil and probiotics (Vizylac, lactic acid Bacillus), and 2\% ketoconazole were applied on filter paper discs of $6 \mathrm{~mm}$ separately $(4.0 \mu \mathrm{L} /$ disc $)$ and allowed to dry.

Suspensions of $C$. albicans were prepared in saline solution adjusted to the turbidity of $0.5 \mathrm{McF}$ arland and streaked onto Mueller-Hinton agar supplemented with $1 \%$ glucose evenly. Then the discs of chlorhexidine, coconut oil, probiotics, and ketoconazole are placed on its surface at equal distance. This was done for all the 20 isolates of Candida. Then the plates were incubated at $37^{\circ} \mathrm{C}$ for 24 hours and observed for the zone of inhibition around the disc (Figure 2), which will be measured and compared.

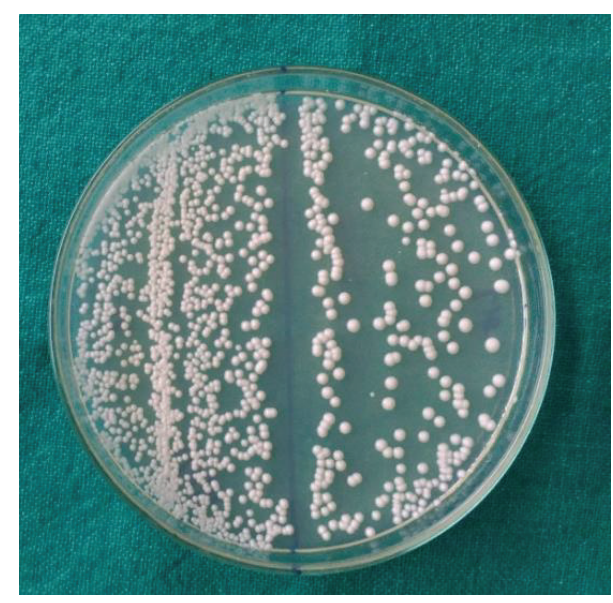

FIgURE 1: Candidal growth on SDA.

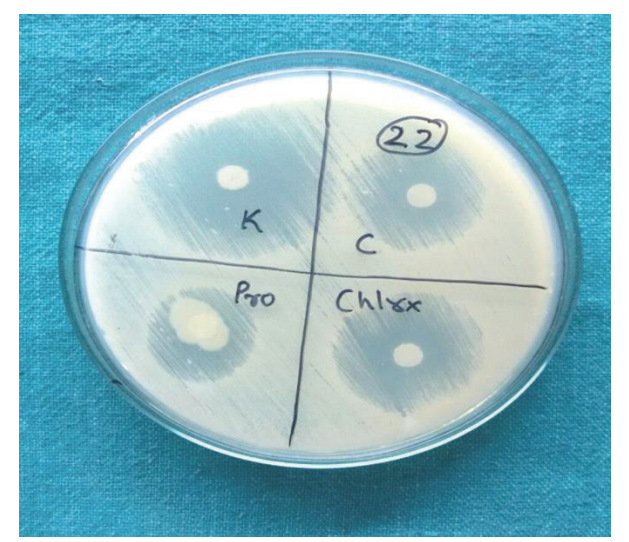

Figure 2: Zone of inhibition observed around the disc.

\section{Results}

Candida was identified by its morphological features of cream, smooth, pasty convex colonies on SDA. Germ tube formation and the formation of conidiospores confirmed the presence of $C$. albicans. The antifungal susceptibility test showed that C. albicans was susceptible to ketoconazole, chlorhexidine, coconut oil, and probiotics by having a clear zone of inhibition.

3.1. Data Analysis. The phenotypes and the susceptibility of the isolates to the antifungals were compared against one another by the nonparametric Kruskal-Wallis, for multiple independent groups, or Mann-Whitney, for two independent groups, tests.

Table 1 shows comparison of zone of inhibition between different groups. It was found that the mean zone of inhibition for chlorhexidine was $21.8 \mathrm{~mm}$, whereas for coconut oil it was $16.8 \mathrm{~mm}$, for probiotics it was $13.5 \mathrm{~mm}$, and for ketoconazole it was $22.3 \mathrm{~mm}$ (Figure 3). The difference between the groups was not statistically significant (Chi-square value $7.42, P$ value $0.06)$. 
TABLE 1: Comparison of zone of inhibition between different groups.

\begin{tabular}{lccccc}
\hline & $N$ & Mean & Std. deviation & Chi-square & $P$ value \\
\hline Chlorhexidine & 20 & 21.80 & 8.458 & & \\
Coconut oil & 20 & 16.80 & 12.846 & & \\
Probiotics & 20 & 13.50 & 13.656 & 7.429 & $0.059_{\text {NS }}$ \\
Ketoconazole & 20 & 22.30 & 15.076 & & \\
Total & 80 & 18.60 & 13.033 & & \\
\hline
\end{tabular}

NS: not significant Kruskal-Wallis ANOVA.

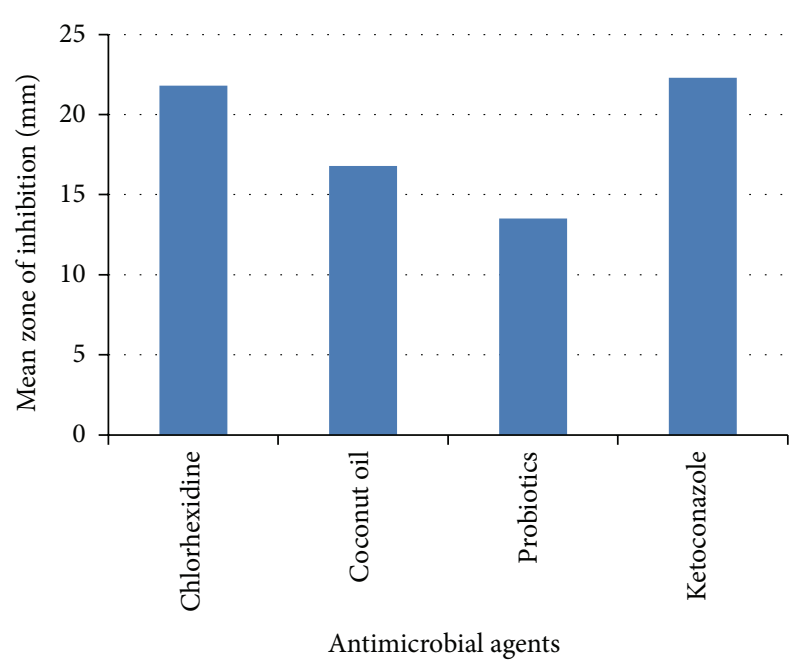

FIGURE 3: Mean of zone of inhibition of the antimicrobial agents against Candida albicans.

The zone of inhibition between CHX and ketoconazole is compared in Table 2. It was found that the mean zone of inhibition for chlorhexidine was $21.8 \mathrm{~mm}$, whereas for ketoconazole it was $22.3 \mathrm{~mm}$. The difference between the groups was not statistically significant ( $P$ value 0.54 ). Comparison of zone of inhibition between coconut oil and ketoconazole is shown in Table 3 . The results show that the mean zone of inhibition for coconut oil was $12.8 \mathrm{~mm}$, whereas for ketoconazole it was $22.3 \mathrm{~mm}$. The difference between the groups was not statistically significant ( $P$ value 0.07 ). The zone of inhibition of probiotics and ketoconazole is shown in Table 4. A variation could be observed here as it shows that the mean zone of inhibition for probiotics was $13.5 \mathrm{~mm}$ whereas for ketoconazole it was $22.3 \mathrm{~m}$ and the difference between the groups was statistically significant $(P$ value 0.02$)$.

\section{Discussion}

The high incidence of sweetened substances in the diet of the children accompanied by poor oral hygiene, presence of caries lesions, and prolonged use of feeding bottles and pacifiers are the major factors related to the high prevalence of $C$. albicans in children. The highest colonisation site for $C$. albicans is provided by the carious lesion because it provides an ecologic niche for this microorganism [10].
Ketoconazole is an antifungal imidazole compound that has a significant activity against a broad range of superficial and systemic infections caused by pathogenic yeasts, dermatophytes, and filamentous fungi, including $C$. albicans. It stimulates phagocytosis and inhibits the filamentous growth of C. albicans [11]. The primary site of action of ketoconazole is shown as the inhibition of C. albicans respiration by inhibiting the activity of NADH oxidase at the mitochondrial level [12]. It causes direct membrane damage to C. albicans cells and inhibition of ergosterol biosynthesis, which is a characteristic constituent of yeast cell membranes. Hence, in the present study, ketoconazole is taken as the standard antifungal agent, against which other antimicrobial agents are tested.

Chlorhexidine digluconate is used as a broad spectrum antiseptic often incorporated in mouth rinses. It has a broad spectrum of activity against a variety of organisms, including C. albicans [13]. Biofilms on oral surfaces (dental plaque) are responsible for caries and periodontal disease. Chlorhexidine is capable of inhibiting candidal adhesion to biological and inert surfaces [14]. It acts as a fungicide and has a fungistatic function, leading to the coagulation of nucleoproteins and changes in cell walls allowing the possible escape of cytoplasmic components through the plasmalemma [15]. In the present study chlorhexidine showed significant antimicrobial activity against $C$. albicans with a mean zone of inhibition of $21.8 \mathrm{~mm}$, and the difference with that of ketoconazole was not statistically significant ( $P$ value 0.54 ). In a similar study by Machado et al. [13] chlorhexidine solutions showed a reduction in the colony forming units of Candida biofilm.

Coconut oil is known to exhibit antimicrobial activity against $S$. mutans and C. albicans [16]. It has a unique role in the diet as an important physically functional food and is composed of medium chain fatty acids. It contains $92 \%$ saturated fatty acids, approximately $50 \%$ of which is lauric acid [17]. Monolaurin and other medium chain monoglycerides are shown to have the capacity to alter microbial cell walls, penetrate and disrupt cell membranes, and inhibit enzymes involved in energy production and nutrient transfer, leading to the death of the bacteria [18]. Bergsson et al. showed the susceptibility of Candida albicans to several fatty acids and their 1-monoglycerides [19]. In the present study coconut oil has shown antifungal activity that is comparable to that of ketoconazole. C. albicans was found to be highly susceptible to coconut oil in a similar study by Ogbolu et al. [20]. Coconut oil is also known to cause a significant reduction in gingivitis which can be attributed to decreased plaque accumulation and the anti-inflammatory, emollient effect of coconut oil [21].

According to a WHO/FAO report (2002), probiotics are "live micro-organisms which, when administered in adequate amounts, confer a health benefit on the host." Use of probiotics and molecular genetics to replace and displace cariogenic bacteria with noncariogenic bacteria has shown promising results. Hatakka et al. [22] showed a reduced prevalence of C. albicans after taking probiotics in cheese. Results obtained by Kõll et al. [23] were markedly different, where it was reported that the growth of $C$. albicans was not inhibited by the probiotics. In the present study it has been found that probiotics inhibited the growth of C. albicans. However, it 
TABLE 2: Comparison of zone of inhibition between CHX and ketoconazole.

\begin{tabular}{llccccc}
\hline & $N$ & Mean & Std. deviation & Mean difference & $Z$-value & $P$ value \\
\hline Chlorhexidine & 20 & 21.80 & 8.458 & -0.5 & -0.611 \\
Ketoconazole & 20 & 22.30 & 15.076 & & 0.542 \\
\hline
\end{tabular}

${ }^{*}$ Mann-Whitney $U$ test.

TABLE 3: Comparison of zone of inhibition between coconut oil and ketoconazole.

\begin{tabular}{lllcccr}
\hline & $N$ & Mean & Std. deviation & Mean difference & $Z$-value & $P$ value \\
\hline Coconut oil & 20 & 16.80 & 12.846 & -5.5 & -1.761 \\
Ketoconazole & 20 & 22.30 & 15.076 & & 0.078 \\
\hline
\end{tabular}

*Mann-Whitney $U$ test.

TABLE 4: Comparison of zone of inhibition between probiotics and ketoconazole.

\begin{tabular}{llccccc}
\hline & $N$ & Mean & Std. deviation & Mean difference & $Z$-value & $P$ value \\
\hline Probiotics & 20 & 13.50 & 13.656 & -8.8 & -2.272 \\
Ketoconazole & 20 & 22.30 & 15.076 & & 0.023 \\
\hline
\end{tabular}

${ }^{*}$ Mann-Whitney $U$ test.

was lesser than that of chlorhexidine and coconut oil. The difference in the zone of inhibition with ketoconazole was statistically significant.

\section{Conclusion}

This study scientifically proves the antifungal activity of chlorhexidine, coconut oil, and probiotics. The antifungal activity of coconut oil is found to be higher than that of probiotics against C. albicans. Further studies must be carried out to determine the antimicrobial efficacy, the MIC, and MFC of these agents and more clinical studies have to be conducted to validate the same.

\section{Competing Interests}

The authors report no competing interests.

\section{References}

[1] American Academy of Pediatric Dentistry, "Policy on Early Childhood Caries (ECC): Classifications, Consequences, and Preventive strategies," http://www.aapd.org/media/Policies_ Guidelines/P_ECCClassifications.pdf.

[2] S. Marchant, S. R. Brailsford, A. C. Twomey, G. J. Roberts, and D. Beighton, "The predominant microflora of nursing caries lesions," Caries Research, vol. 35, no. 6, pp. 397-402, 2001.

[3] Y. Li and A. Tanner, "Effect of antimicrobial interventions on the oral microbiota associated with early childhood caries," Pediatric Dentistry, vol. 37, no. 3, pp. 226-244, 2015.

[4] T. Klinke, S. Kneist, J. J. de Soet et al., "Acid production by oral strains of Candida albicans and lactobacilli," Caries Research, vol. 43, no. 2, pp. 83-91, 2009.

[5] D. D. S. V. Barbieri, V. A. Vicente, F. C. Fraiz, O. J. Lavoranti, T. I. E. Svidzinski, and R. L. Pinheiro, "Analysis of the in vitro adherence of Streptococcus mutans and Candida albicans,"
Brazilian Journal of Microbiology, vol. 38, no. 4, pp. 624-631, 2007.

[6] H. Minagawa, K. Kitaura, and N. Nakamizo, "Effects of pH on the activity of ketoconazole against Candida albicans," Antimicrobial Agents and Chemotherapy, vol. 23, no. 1, pp. 105107, 1983.

[7] P. A. Suci and B. J. Tyler, "Action of chlorhexidine digluconate against yeast and filamentous forms in an early-stage Candida albicans biofilm," Antimicrobial Agents and Chemotherapy, vol. 46, no. 11, pp. 3522-3531, 2002.

[8] M. DebMandal and S. Mandal, "Coconut (Cocos nucifera L.: Arecaceae): in health promotion and disease prevention," Asian Pacific Journal of Tropical Medicine, vol. 4, no. 3, pp. 241-247, 2011.

[9] S. Saha, C. Tomaro-Duchesneau, M. Tabrizian, and S. Prakash, "Effects of $\mathrm{pH}$ on the activity of ketoconazole against Candida albicans," Expert Opinion on Biological Therapy, vol. 12, no. 9, pp. 1207-1220, 2012.

[10] F. G. De Carvalho, T. M. Parisotto, J. Hebling, L. C. Spolidorio, and D. M. P. Spolidorio, "Presence of Candida spp. in infants oral cavity and its association with early childhood caries," Brazilian Journal of Oral Sciences, vol. 6, no. 20, pp. 1249-1253, 2007.

[11] J. Uno, M. L. Shigematsu, and T. Arai, "Primary site of action of ketoconazole on Candida albicans," Antimicrobial Agents and Chemotherapy, vol. 21, no. 6, pp. 912-918, 1982.

[12] H. Bobichon and P. Bouchet, "Action of chlorhexidine on budding Candida albicans: scanning and transmission electron microscopic study," Mycopathologia, vol. 100, no. 1, pp. 27-35, 1987.

[13] F. C. Machado, M. B. Portela, A. C. Cunha, I. P. R. Souza, R. M. Soares, and G. F. Castro, "Antifungal activity of chlorhexidine on Candida spp. Biofilm," Revista de Odontologia da UNESP, vol. 39, no. 5, pp. 271-275, 2010.

[14] A. N. B. Ellepola and L. P. Samaranayake, "Adjunctive use of chlorhexidine in oral candidoses: a review," Oral Diseases, vol. 7, no. 1, pp. 11-17, 2001.

[15] S. Carvalhinho, A. M. Costa, A. C. Coelho, E. Martins, and A. Sampaio, "Susceptibilities of Candida albicans mouth isolates 
to antifungal agents, essentials oils and mouth rinses," Mycopathologia, vol. 174, no. 1, pp. 69-76, 2012.

[16] S. Thaweboon, J. Nakaparksin, and B. Thaweboon, "Effect of oilpulling on oral microorganisms in biofilm models," Asia Journal of Public Health, vol. 2, no. 2, pp. 62-66, 2011.

[17] D. J. Pehowich, A. V. Gomes, and J. A. Barnes, "Fatty acid composition and possible health effects of coconut constituents," West Indian Medical Journal, vol. 49, no. 2, pp. 128-133, 2000.

[18] V. M. Verallo-Rowell, K. M. Dillague, and B. S. SyahTjundawan, "Novel antibacterial and emollient effects of coconut and virgin olive oils in adult atopic dermatitis," Dermatitis, vol. 19, no. 6, pp. 308-315, 2008.

[19] G. Bergsson, J. Arnfinnsson, Ó. Steingrímsson, and H. Thormar, "In vitro killing of Candida albicans by fatty acids and monoglycerides," Antimicrobial Agents and Chemotherapy, vol. 45, no. 11, pp. 3209-3212, 2001.

[20] D. O. Ogbolu, A. A. Oni, O. A. Daini, and A. P. Oloko, "In vitro antimicrobial properties of coconut oil on Candida species in Ibadan, Nigeria," Journal of Medicinal Food, vol. 10, no. 2, pp. 384-387, 2007.

[21] F. C. Peedikayil, P. Sreenivasan, and A. Narayanan, "Effect of coconut oil in plaque related gingivitis-a preliminary report," Nigerian Medical Journal, vol. 56, no. 2, pp. 141-147, 2015.

[22] K. Hatakka, A. J. Ahola, H. Yli-Knuuttila et al., "Probiotics reduce the prevalence of oral candida in the elderly-a randomized controlled trial," Journal of Dental Research, vol. 86, no. 2, pp. 125-130, 2007.

[23] P. Kõll, R. Mändar, H. Marcotte, E. Leibur, M. Mikelsaar, and L. Hammarström, "Characterization of oral lactobacilli as potential probiotics for oral health," Oral Microbiology and Immunology, vol. 23, no. 2, pp. 139-147, 2008. 


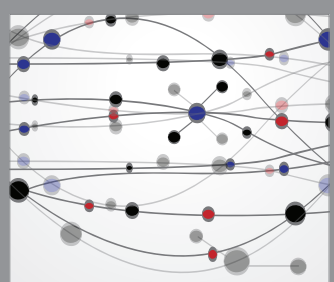

The Scientific World Journal
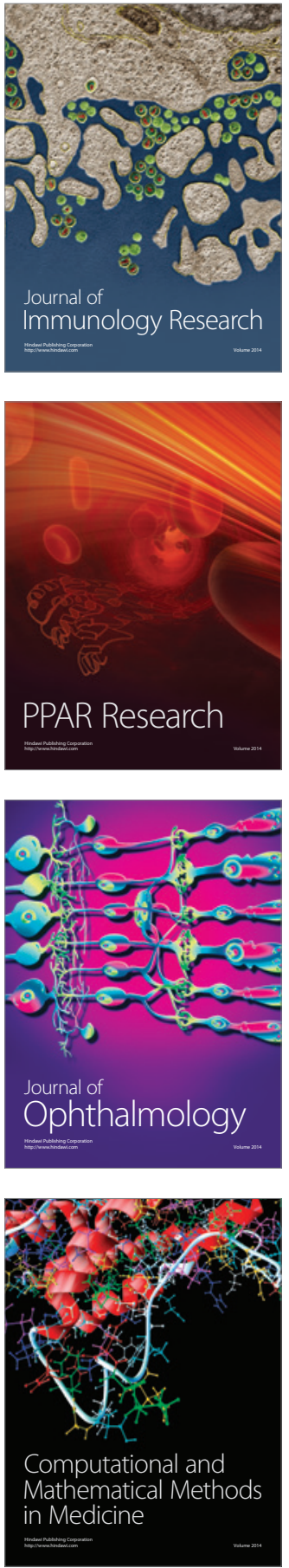

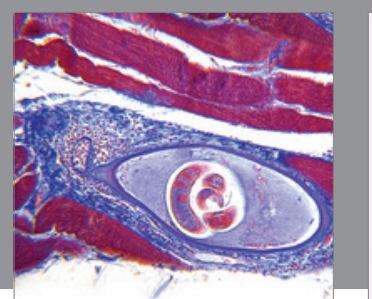

Gastroenterology Research and Practice

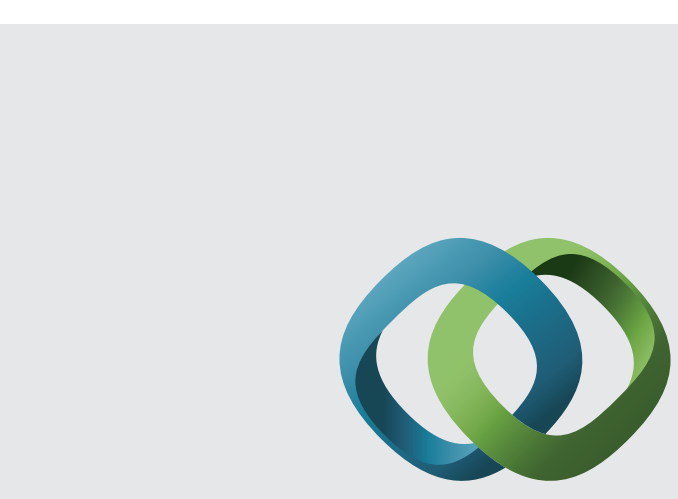

\section{Hindawi}

Submit your manuscripts at

http://www.hindawi.com
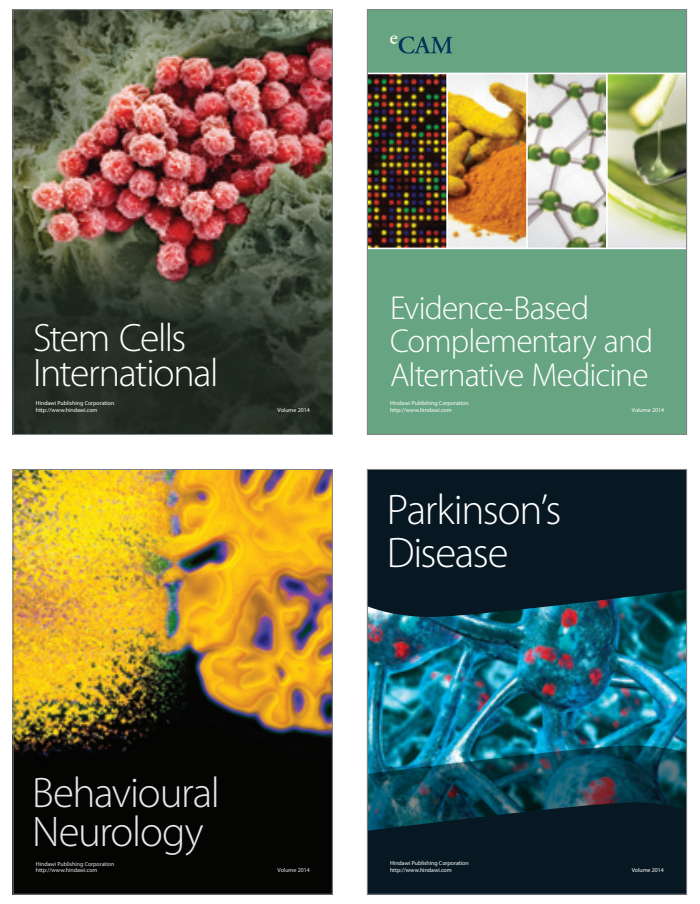
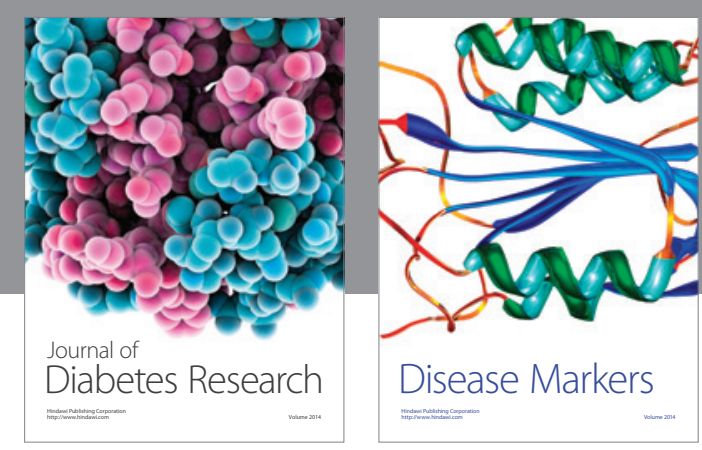

Disease Markers
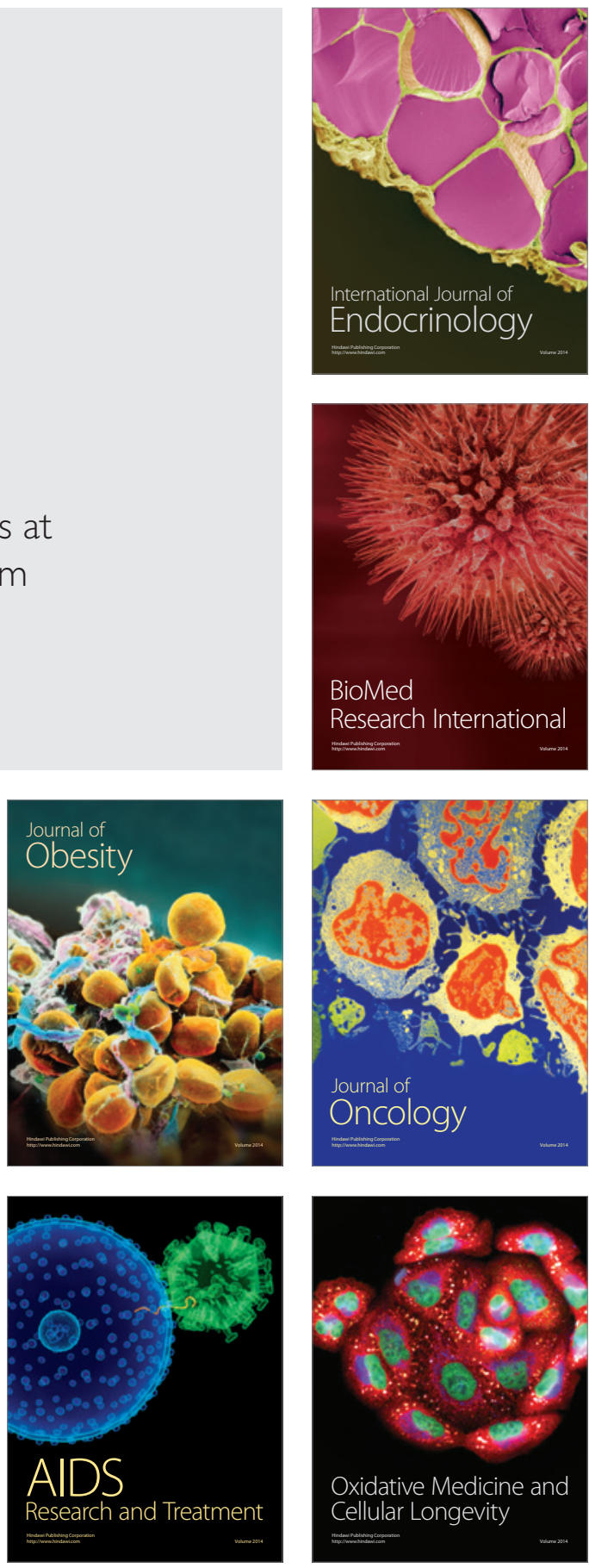